\title{
Experimental Study on the Rate Correlativity of Particulate-filled Composite
}

\author{
HU Shao- qing, XU Jin-sheng, HAN Long, ZHOU Chang-sheng
}

School of mechanical engineering, Nanjing university of science \& technology,

Nanjing 210094, China.

309010207@njust.edu.cn

Keywords: particulate-filled composite, strain rate effect, mechanical property, initial modulus

\begin{abstract}
The effects of strain rate on the mechanical properties of the particulate-filled composite have been studied. Tests in uniaxial tensile condition were carried out over a range of tensile rates. Results show that the mechanical properties of the particulate-filled composite are distinctly influenced by strain rate. Yield stress, initial modulus, and fracture stress increase linearly with the logarithm of strain rate. But yield strain is less sensitive to strain rate.
\end{abstract}

\section{Introduction}

Composite propellant, as a kind of typical high-particulate-filled composite, is composed of adhesive system and fuel particles, which would result in the nonuniform of its microstructure. This special microstructure may be the leading cause of the complex mechanical performance ${ }^{[1]}$. Under finite deformation, the dewetting of the particle ${ }^{[2-4]}$ would lead to the nonlinearity of the stress-strain relationship. The cavities caused by dewetting are the main characteristic if the dilatation. S. Özüpek ${ }^{[1,5]}$ and E.J.S.Duncan ${ }^{[6]}$ pointed out that investigation on the rate correlativity of the particulate-filled composite was the foundation of its application and the essential mean for the constitutive model study. Zhang $\mathrm{J} \mathrm{B}^{[7-9]}$ studied the rate correlativity of double based propellant under various conditions, such as uniaxial tensile and compression condition and high rates condition. Wang $\mathrm{Y} \mathrm{Y}^{[10]}$ and Lai $\mathrm{J} \mathrm{W}^{[11]}$ analysis the influences of the strain rates on the dissipated energy of composite propellant. Guo $\mathrm{X}^{[14]}$ investigated on the breaking strain and breaking stress change under different strain rates. But the study didn't involve in the difference of the stress-strain relationship.

Based on the study of predecessors, the influence of the strain rates on the mechanical properties of composite propellant was studied, to lay a foundation of the study on the constitutive model.

\section{Experimental material and method}

Composite propellant, as a heterogeneous propellant, the differences of formula would cause the change of the mechanical properties, but would not have intrinsic distinction ${ }^{[12]}$.Thus, the composite propellant of the same batch, consisting of polyether polyurethane and diethyleneglycol dinitrate as adhesive and ammonium perchlorate, aluminum powder, cyclotetramethylene tetranitramine as fuel particles. Referring to QJ924-85 standard, the material was cut to dumbbell specimens, as pictured in Fig 1. Experiments were carried out on QJ211B electronic universal test machine in room temperature under the tensile rates of $5 \mathrm{~mm} / \mathrm{min}, 20 \mathrm{~mm} / \mathrm{min}, 50 \mathrm{~mm} / \mathrm{min}$, $100 \mathrm{~mm} / \mathrm{min}, 200 \mathrm{~mm} / \mathrm{min}, 500 \mathrm{~mm} / \mathrm{min}$.

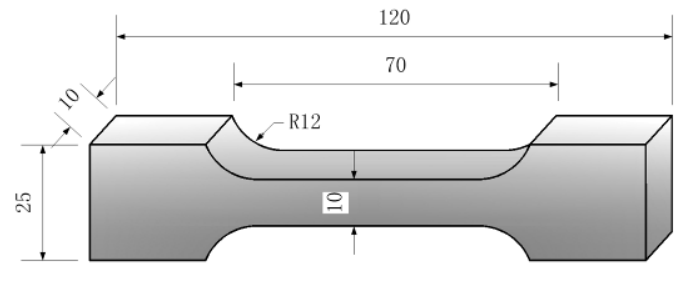

Fig 1 Diagram of test specimen 


\section{Experimental results}

\subsection{Typical stress-strain curve}

Fig 2 illustrates the typical stress-strain curve for the composite propellant. The stress-strain curve exhibits an initial elastic response followed by yielding and strain harding. The curve could be divided into three parts, elastic strain region, yielding region , strain harding region, using double tangent method as shown in Fig 2. The strain at point A should be viewed as yield strain Es, and the corresponding stress should be yield stress $\varepsilon_{s}$. Serial other mechanical parameter could be acquire, initial modulus $E_{i n}$, breaking strain $\varepsilon_{m}$ and breaking stress $\sigma_{m}$. as shown in Fig 2 .

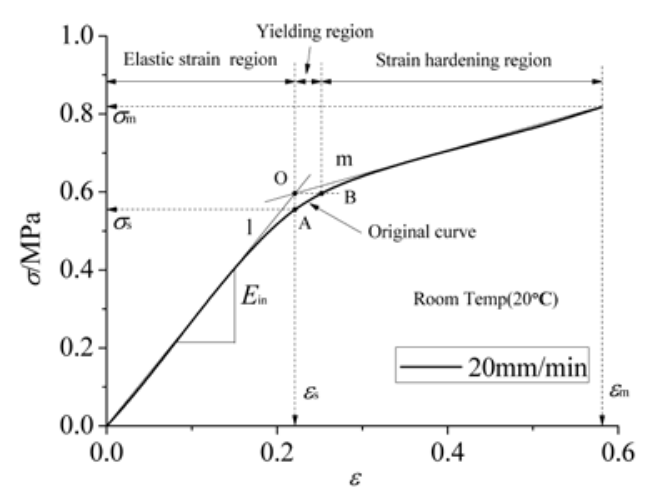

Fig 2 Stress-strain response at $20 \mathrm{~mm} / \mathrm{min}$

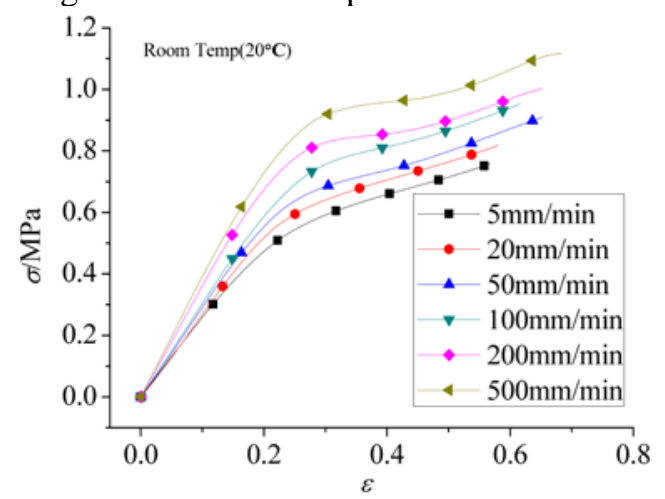

Fig 3 Stress-strain responses at different strain rates

The corresponding stress versus strain behavior shows the expected increase in initial slop representing modulus and yield stress increase with the strain rate, as shown in Fig 3. But a dramatic softening at high strain rate is observed after yield due to the combined result of strain softening and thermal softening.

3.2 Rate dependence of yield strain

The yield strain of all specimens was collected, as shown in Table 1. It is obvious that there is little difference between different groups. The ANOVA of yield strain turns out that yield strain are not changed with the strain rates, the mean of the yield strain equals 0.205.

Table 1 Collection of yield strain

\begin{tabular}{cccccc}
\hline $5 \mathrm{~mm} / \mathrm{min}$ & $20 \mathrm{~mm} / \mathrm{min}$ & $50 \mathrm{~mm} / \mathrm{min}$ & $100 \mathrm{~mm} / \mathrm{min}$ & $200 \mathrm{~mm} / \mathrm{min}$ & $500 \mathrm{~mm} / \mathrm{min}$ \\
\hline 0.205 & 0.203 & 0.194 & 0.178 & 0.185 & 0.238 \\
0.208 & 0.192 & 0.200 & 0.213 & 0.178 & 0.216 \\
0.186 & 0.188 & 0.209 & 0.198 & 0.177 & 0.184 \\
0.200 & 0.190 & 0.192 & 0.204 & 0.206 & 0.222 \\
0.196 & 0.193 & 0.199 & 0.200 & 0.185 & 0.218 \\
\hline
\end{tabular}

3.3 Rate dependence of breaking strain

The breaking strain of all specimens was collected, as shown in Table 2. It is obvious that there is little difference between different groups. The ANOVA of breaking strain turns out that breaking strain are not changed with the strain rates, the mean of the breaking strain equals 0.630. 
Table 2 Collection of breaking strain

\begin{tabular}{cccccc}
\hline $5 \mathrm{~mm} / \mathrm{min}$ & $20 \mathrm{~mm} / \mathrm{min}$ & $50 \mathrm{~mm} / \mathrm{min}$ & $100 \mathrm{~mm} / \mathrm{min}$ & $200 \mathrm{~mm} / \mathrm{min}$ & $500 \mathrm{~mm} / \mathrm{min}$ \\
\hline 0.595 & 0.547 & 0.652 & 0.508 & 0.656 & 0.600 \\
0.5455 & 0.633 & 0.684 & 0.712 & 0.648 & 0.692 \\
0.582 & 0.586 & 0.679 & 0.581 & 0.491 & 0.734 \\
0.595 & 0.555 & 0.697 & 0.600 & 0.795 & 0.728 \\
0.621 & 0.580 & 0.678 & 0.681 & 0.672 & 0.658 \\
\hline
\end{tabular}

3.4 Rate dependence of initial modulus, yield stress, breaking stress

There is distinct rate dependence of initial modulus, yield stress, breaking stress, the mean values of which are shown in Table 3.

Table 3 Collection of mechanical parameter

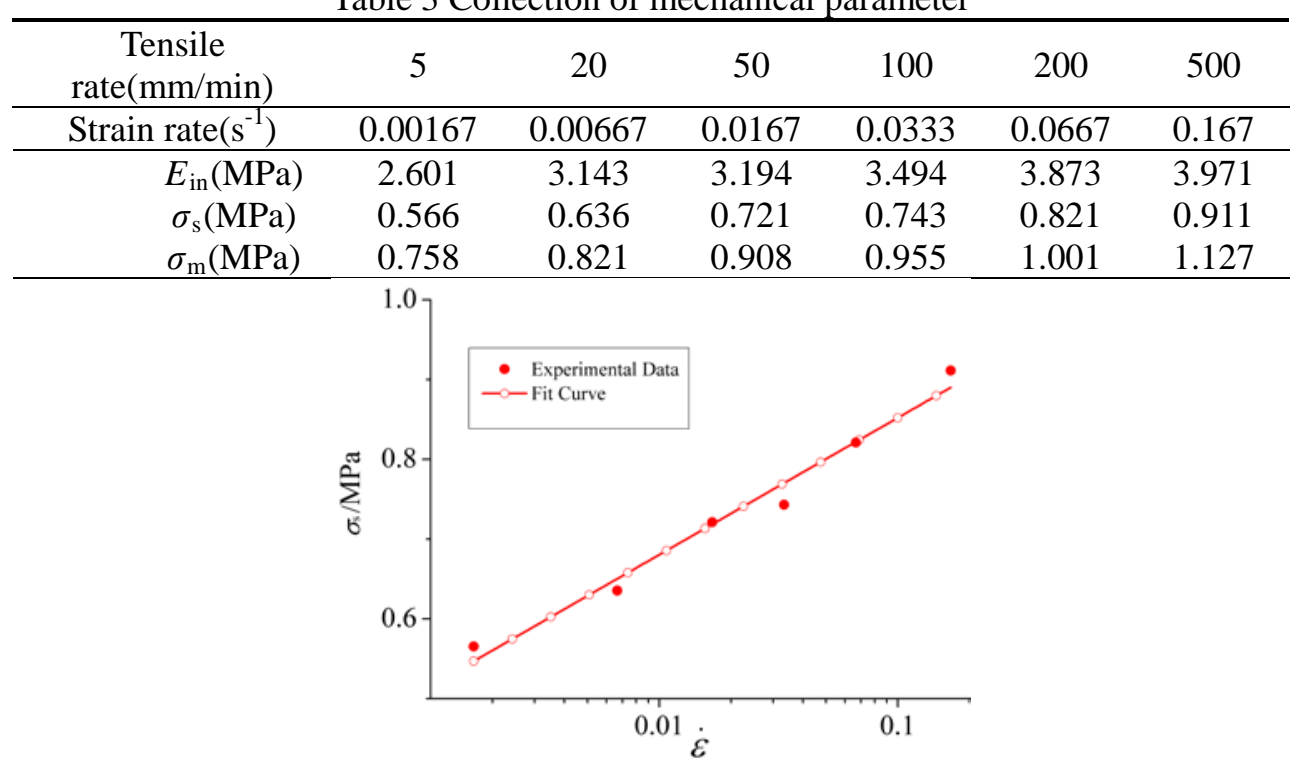

Fig.4 Fit curve and test data for yield stress

On the basis of Eyring flow model, the relationship between yield stress and strain rates could be written as

$$
\sigma_{\mathrm{s}}=\sqrt{3} \tau_{0} \ln \left(2 \sqrt{3} A_{0}\right)+\sqrt{3} \tau_{0} \ln \dot{\varepsilon}
$$

Where $A_{0}$ and $\tau_{0}$ are material parameters. The yield stress at different strain rates were fitted by minimization of least square of errors using equation (1), as shown in Fig 4

Similar equation was grabbed to fit initial modulus and breaking stress at different strain rates, as shown in Fig 5 and Fig 6. It is observed that Yield stress, initial modulus, and fracture stress increase linearly with the logarithm of strain rate.

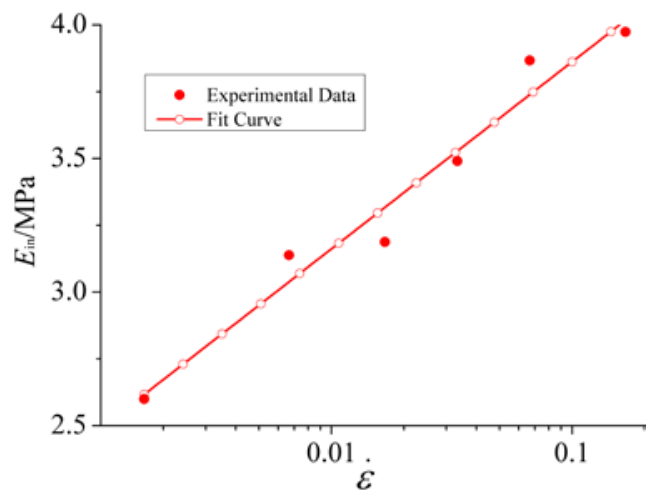

Fig 5 Fit curve and test data for initial modulus 


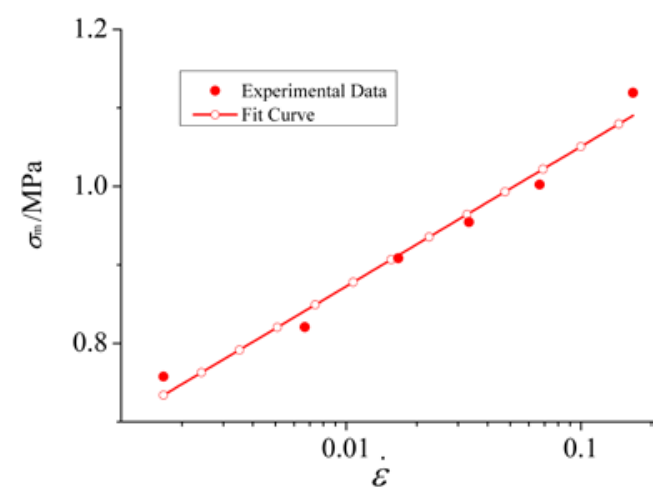

Fig 6 Fit curve and test data for fracture stress

\section{Summary}

The effects of strain rate on the mechanical properties of the particulate-filled composite have been studied. Tests in uniaxial tensile condition were carried out over a range of tensile rates. Results show that the mechanical properties of the particulate-filled composite are distinctly influenced by strain rate. Yield stress, initial modulus, and fracture stress increase linearly with the logarithm of strain rate. But yield strain is less sensitive to strain rate.

\section{Acknowledgement}

Dr. XU Jin-sheng is the corresponding author of this paper. I would like to thank Mr Gao Yanbin for helping with the experiment.

\section{Reference}

[1]Ş. Özüpek and E. Becker. Constitutive modeling of high-elongation solid propellants [J]. Journal of Engineering Materials and Technology, 1992, 114: 111-115.

[2]R. Farris. The influence of vacuole formation on the response and failure of filled elastomers[J]. Transactions of The Society of Rheology (1957-1977), 1968, 12(2): 315-334.

[3]L. R. Cornwell and R. A. Schapery. SEM study of microcracking in strained solid propellant[J]. Metallography, 1975, 8(5): 445-452.

[4]L. A. Vratsanos and R. J. Farris. A predictive model for the mechanical behavior of particulate composites. Part I: Model derivation[J]. Polymer Engineering \& Science, 1993, 33(22): 1458-1465.

[5]Ş. Özüpek. Constitutive Equations for Solid Propellants[D]. Austin: University of Texas at Austin, 1995.

[6]E. J. S. Duncan and J. Margetson. A Nonlinear Viscoelastic Theory for Solid Rocket Propellants Based on a Cumulative Damage Approach [J]. Propellants, Explosives\& Pyrotechnics, 1998, 23(2): 94-104.

[7]Hu Shao-qing, et al. Effects of strain rates on mechanical properties of DBP under uniaxial compression condition[J]. Journal of Ballistics, 2011, 23(4): 75-79.

[8]ZHANG Jian-bin, et al. Study on Rate Correlativity of Double-Base Solid Propellant[J]. Journal of Ballistics, 2011, 23(4): 80-83.

[9]SUN Chao-xiang, et al. Experimental Research on the Compressive Properties of Modified Double Base Propellant at Low and High Strain Rates [J]. Acta Armamentarii, 2013, 34(6): 698-703.

[10]WANG Yu-feng,et al. Effect of Strain Rate and Loading on Mechanical Properties and Dissipated Energy for HTPB Propellant[J]. Chinese Journal of Energetic Materials , 2010, 18(4): 
377-382.

[11LAI Jian-wei, et al. Effects of low temperature and strain rate on compressive mechanical properties of HTPB propellant[J]. Journal of Solid Rocket Technology, 2012, 35(6): 792-794,798.

[12]R. Manjari, et al. Structure-property relationship of HTPB-based propellants. II. Formulation tailoring for better mechanical properties[J]. Journal of Applied Polymer Science, 1993, 48(2): 279-289. 